\title{
Ozone pre-oxidation to the degradation technology research of MC-LR under the condition of different $\mathrm{pH}$
}

\author{
Yingzi Lin ${ }^{\mathrm{a}}$, Mingli Chen ${ }^{\mathrm{b}}$, Guan Li ${ }^{\mathrm{c}}$ \\ School of Municipal and Environmental Engineering institute, Jilin Jianzhu University, Changchun \\ 130118, China \\ aLinyingzi1000@163.com, ${ }^{\mathrm{b}} \mathrm{cml} 629 @ 126 . c o m,{ }^{\mathrm{c}}$ strliguan@163.com
}

Keywords: drinking water; algae; algal toxins; removal; Ph.

\begin{abstract}
Ozone pre-oxidation removal of MC-LR better, under the condition of pH4,ozone for MC-LR removal of $76.22 \%$, than the original water removal increased by about $11 \%$.With the increasing value of $\mathrm{pH}$, ozone for MC-LR removal decreased, but higher $\mathrm{pH}$ beneficial ozone removal of turbidity, UV254, TOC and CODMn. In the pH10,ozone dosage of $2 \mathrm{mg} / \mathrm{L}$ case, turbidity, UV254, TOC and CODMn removal rates were 33.75\%, $41.88 \%, 12.68 \%$ and $11.43 \%$, the removal has been enhanced than the original water.
\end{abstract}

\section{Introduction}

Algal toxins is a cyclic heptapeptide substance, there is a strong heat resistance ${ }^{[1]}$ and can withstand extreme $\mathrm{pH}$, natural degradation speed is very slow ${ }^{[2,3]}$. Microcystin isomers are about more than 60 kinds, which the widely distributed and the representative of microcystin (Microcystin, namely MC). Especially MC-LR, the widely distributed, and the strongest toxicity .World Health Organization (WHO) ${ }^{[4]}$ recommended the algal toxins in drinking water standard for MC-LR should be less than $1.0 \mu \mathrm{g} / \mathrm{L}$. Our country provides MC-LR limit of $1 \mu \mathrm{g} / \mathrm{L}$ in drinking Water Standards 2012. The study found that ozone on algal toxin has good removal effect Hengfeng Miao ${ }^{[4]}$ and other analysts believe,in the $\mathrm{O}_{3}$ : MC is 6, MC - LR removal efficiency can reach 92\%,the study found that Kejia Zhang ${ }^{[5]}$, etc, the degradation of ozone in MC - LR pseudo-first-order reaction kinetics, the ozone dosing quantity increased from $0.31 \mathrm{mg} / \mathrm{L}$ to $0.31 \mathrm{mg} / \mathrm{L}, \mathrm{MC}$ - LR degradation rate increased by $0.0103 \mathrm{~min}^{-1}$ to $0.0407 \mathrm{~min}^{-1}$, and the acidic conditions more conducive to MC-LR removal. The experiment mainly to study the ozone removal of MC-LR, and analyze the different $\mathrm{pH}$ conditions, The influence of ozone on MC - LR.

\section{Materials and Methods}

\subsection{Experimental Materials}

Experiments with water taken from a water source of raw water of the north, through the cultivation of algae.MC-LR standard solution (20ug / L) was purchased from scientific testing by the Environmental Protection Department of Agriculture. Trifluoroacetic acid (purity > 99\%) was purchased from Scharlau Company, methanol and other agents were of analytical grade.

\subsection{Experimental apparatus and method}

Using high performance liquid chromatography (HPLC) of Agilent 1200C for MC-LR was measured, measurement parameters: the injection volume was $20 \mathrm{uL}$; UV-visible detector wavelength $238 \mathrm{~nm}$; column temperature was $25{ }^{\circ} \mathrm{C}$; mobile phase $0.05 \%$ TFA aqueous solution/Methanol is 45/55; the flow rate was $1.0 \mathrm{ml} / \mathrm{min}$. Application of ozone generator (3S-A3), through iodometric method to measure the concentration of ozone, Control the ozone dosing quantity is $1 \mathrm{mg} / \mathrm{L}, 2 \mathrm{mg} / \mathrm{L}, 3 \mathrm{mg} / \mathrm{L}, 4$ $\mathrm{mg} / \mathrm{L}, 5 \mathrm{mg} / \mathrm{L}$, the reaction time was $30 \mathrm{~min}$, the reaction temperature using room temperature is $25{ }^{\circ} \mathrm{C}$, and observe the response to the phenomenon. Determination of MC - LR containing algae water quality concentration is $5.3 \mathrm{ug} / \mathrm{L}$. The TOC - VCPN total organic carbon analyzer of island Ferry Company to measure the TOC, measurement of turbidity using HACH 2100N turbidity analyzers, 
$\mathrm{UV}_{254}$ measured using CV-1700 UV-visible spectrophotometer. Water containing algae water quality characteristics are shown in table 1.

Table 1 raw water quality characteristics

\begin{tabular}{|c|c|c|c|c|c|}
\hline $\begin{array}{c}\text { turbidity(NTU } \\
)\end{array}$ & $\mathrm{pH}$ & $\mathrm{TOC}(\mathrm{mg} / \mathrm{L})$ & $\mathrm{UV}_{254}\left(\mathrm{~cm}^{-1}\right)$ & $\begin{array}{c}\mathrm{COD}_{\mathrm{Mn}} \\
(\mathrm{mg} / \mathrm{L})\end{array}$ & $\begin{array}{c}\text { MC-LR } \\
(\mathrm{ug} / \mathrm{L})\end{array}$ \\
\hline 3.2 & 9.0 & 7.57 & 0.16 & 5.6 & 5.3 \\
\hline
\end{tabular}

\section{Results and Analysis}

\subsection{The effects of different $\mathrm{pH}$ values by ozone pre-oxidation}

Ozone reflected at different $\mathrm{pH}$ values are distinct, under acidic conditions, a direct reflection of ozone with organic compounds, which are selective oxidation to produce carboxylic acids and some other simple organic matter or direct oxidation processes produce carbon dioxide and water. And under basic conditions, ozone and organic matter belongs indirectly reflects, the ozone production of hydroxyl radicals $(\cdot \mathrm{OH})$ under basic conditions, $(\cdot \mathrm{OH})$ and organic reflecting the rapid and strong oxidized, which are not selective oxidation, direct the organics were oxidized to carbon dioxide and water or an inorganic matter process ${ }^{[6]}$.

Impact of ozone pre-oxidation on MC-LR under different $\mathrm{pH}$ conditions. Separately with sulfuric acid and sodium hydroxide adjust the $\mathrm{pH}$ of raw water to 4, 5.5, 7, 8.5 and 10,ozone dosage of $2 \mathrm{mg} / \mathrm{L}$, reaction time was $30 \mathrm{~min}$, the temperature reacting the using room temperature $25^{\circ} \mathrm{C}$, and observe the reaction phenomena, and retain the remaining water samples to other water quality characteristics were measured.

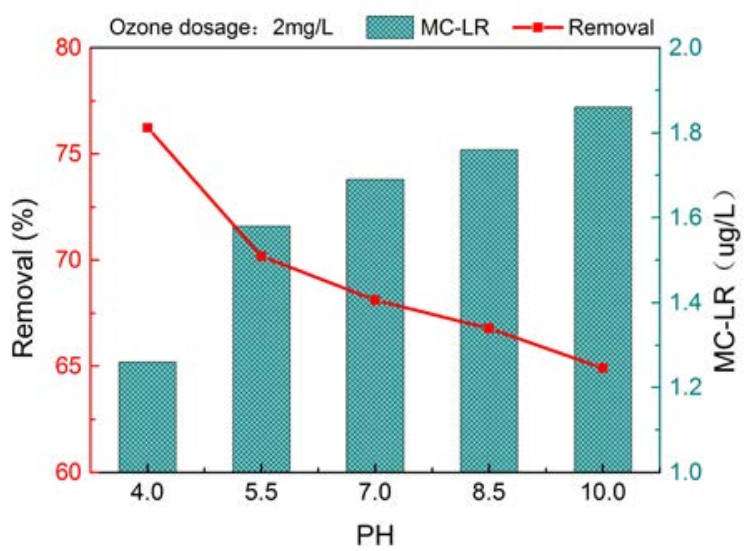

Fig. 1 Ozone pre-oxidation removal of MC-LR under different $\mathrm{pH}$ conditions

Figure 1 shows that the ozone removal efficiency of MC-LR decreases with the increase of $\mathrm{pH}, \mathrm{pH}$ at 4, the ozone removal rate of MC-LR was $76.22 \%$, the reason may be due to the acidic conditions, ozone mainly reflected a direct reaction, due to MC-LR molecules containing large amounts of unsaturated bond, under acidic conditions, the selective oxidation of ozone destroyed unsaturated bond of MC-LR, causing damage to the MC-LR, make it inactivated. And under alkaline conditions, ozone reflects indirectly reaction that $(\cdot \mathrm{OH})$ with organic matter in water reflects, $(\cdot \mathrm{OH})$ does not have a selective oxidation, other organic and algal toxins in the water to form the oxidation of competition, so that MC-LR cannot be effectively removed.

The impact of ozone pre-oxidation on the water quality characteristics under different $\mathrm{pH}$ conditions. The removal of turbidity and UV254 


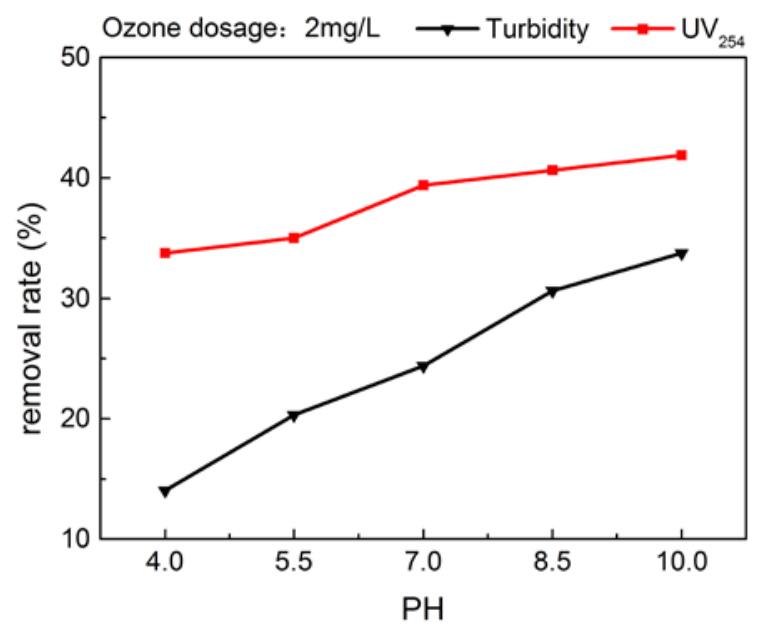

Fig. 2 Ozone pre-oxidation remove of turbidity and UV254 at different pH conditions

Seen from Figure 2,with the increase of $\mathrm{pH}$ value, ozone and water turbidity and $\mathrm{UV}_{254}$ removal rate is also increasing, $\mathrm{pH} 10$, under the conditions, ozone oxidation of $\mathrm{UV}_{254}$ and turbidity removal rate was $33.75 \%$ and $41.88 \%$, likely due to ozone produced under alkaline conditions more conducive $(\cdot \mathrm{OH})$ removal of turbidity and $\mathrm{UV}_{254}$.

The impact of the TOC and CODMn

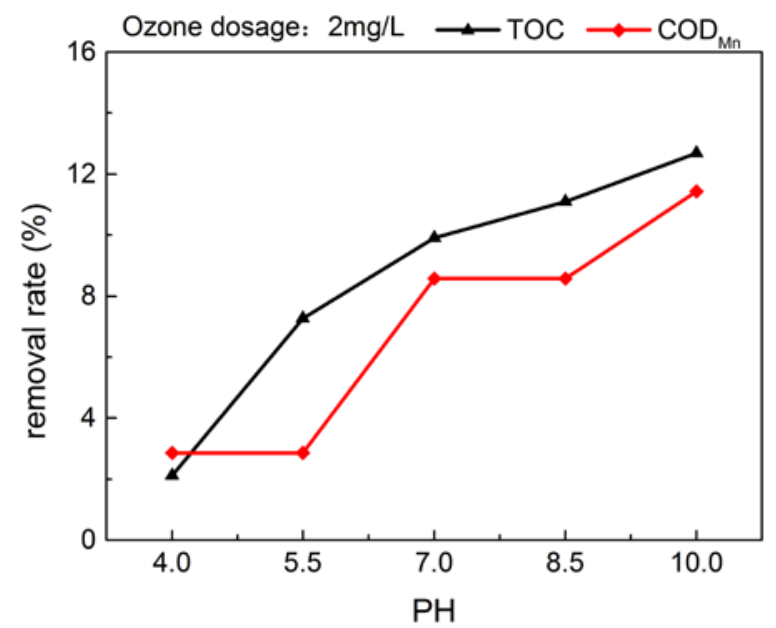

Fig.3 Ozone pre-oxidation remove of TOC and CODMn at different pH conditions

Seen from Figure 3, ozone removal rate of TOC and $\mathrm{COD}_{\mathrm{Mn}}$ with the increase of $\mathrm{pH}$ value, under the condition of $\mathrm{pH}$ for 10 , the ozone removal of TOC and $\mathrm{COD}_{\mathrm{Mn}}$ were $12.68 \%$ and $11.43 \%$, compared with the raw water the removal rate has enhanced. Analysis of the reasons may be due to ozone produced $(\cdot \mathrm{OH})$ under alkaline conditions, $(\cdot \mathrm{OH})$ will organics in water completely oxidized to carbon dioxide and water, thus removal of organic matter.

\section{Conclusion}

Ozone can effectively degrade MC-LR, under the condition of acid can improve the effect of ozone on algal toxin removal, under the condition of $\mathrm{pH} 4,2 \mathrm{mg} / \mathrm{L}$ ozone to MC - LR removal rate reached $76.22 \%$,than the original water removal increased by about $11 \%$.With the increase of $\mathrm{pH}$, ozone to gradually reduce the removal rate of $\mathrm{MC}$ - LR, however, turbidity, $\mathrm{UV}_{254}$, TOC, $\mathrm{COD}_{\mathrm{Mn}}$ removal has been enhanced, in the $\mathrm{pH}$ of 10 ,ozone dosage case $2 \mathrm{mg}$ / $\mathrm{L}$ of ozone on water turbidity, $\mathrm{UV}_{254}$, TOC, $\mathrm{COD}_{\mathrm{Mn}}$ removal rate were $33.75 \%$, 41.88\%, 12.68\%, 11.43\%,the removal has been enhanced than the original water. 


\section{Acknowledgements}

Fund Project: the national water pollution control and governance of science and technology major projects (2012ZX07-408001); Jilin province education department project (2013216).

\section{References}

[1]Z.J. Zhou, X.T. Zheng and Y.S. Zhang: Algae Toxins and Cancer. Carcinog enesis · Distortion · Mutation, Vol 9 (1997) No.6, p.335

[2] Hong-Xing S., Jiu-Hui Q , Ai-Min W. , Et al. : Degradation of Microcystins in Aqueous Solution with in Situ Electrogenerated Active Chlorine. Chemosphere, Vol (2005) No.60, p.326.

[3] Rivasseau C, Martins S, HennionM. C: Determination of some Physicochemical Parameters of Microcystins (Cyanobacterial Toxins) and Trace Level Analysis in Environmental Samples Using Liquid Chromatography. Journal of Chromatography A, Vol (1-2) (1998) No. 799, p.155.

[4] H.F. Miao, X. Lu, Q. Yan, L.J. Xie and W.Q. Ruan: Ozone Degradation Research of Microcystin Algae Toxin- LR [J].Environmental Science, Vol 30 (2009) No.11, p. 3288.

[5] K.J. Zhang, N.Y. Gao, D.D. Yin and M.H. Sui: Dynamics Research of Ozone Oxidation Degra-

dation of Algal Ttoxins - LR [J].Journal of Tongji University (Natural Science Edition), Vol 37 (2009) No.7, p.919.

[6] Y.B. Wu, R.Q. Li, Y.L. Tian, M. An and J.N. Li: The Reaction Mechanism and Influence Factors of Ozone Degradation of Organic Pollutants (POPS) [J].China Environmental Protection Industry, Vol (2010) No .03, p.44. 